\title{
Market Orientation of New Product Development: Assessment of the Impact of Innovative Climate and Culture on Customer Needs in China
}

\author{
Saeed A. Mousa \\ Palestinian Technical University, Tulkarm, Palestine
}

\begin{abstract}
The competition in the worldwide business environment is quite high. The major challenge faced by companies in satisfying the needs of their customers is keeping up with the constant changes in the business arena. Innovation is key to gaining customer loyalty, but is a difficult task in the industry considering how quickly industry trends change. The purpose of this study is to investigate the impacts of this climate and culture of constant innovation on customer needs. The assessment involved the application of two aspects or measures of client needs, namely customer acceptance and loyalty, mainly through the relationship between innovation and brand loyalty. The hypothesis was formed after an extensive literature review and the use of a questionnaire to gather data from 85 respondents. In order to make those responses meaningful data, the questionnaires were then subjected to a simple linear regression. The results of the study show a positive relationship between an innovative climate and culture, and customer needs, satisfaction, and brand loyalty in China. That also indicated a significant association between customers' needs satisfaction and brand loyalty. This study is unique, however, in the sense that it only investigates students as the users of the Chinese mobile market. Therefore, this study provides specific information on a particular demographic within the mobile phone industry.
\end{abstract}

Keywords: brand loyalty, innovation climate, product development

\section{Introduction}

Production of new products with magnificent performance and functionality is the focus of any industry's course of action. In the highly competitive global marketplace, companies must develop new products that meet the changing needs of consumers constantly in order to stay a profitable venture. While creativity is necessary for the development and creation of a new product, innovation results in financial benefits. Innovation in product development, therefore, entails creating a new product; the main aim is to gain a sustainable competitive advantage to satisfy the changing needs of customers (Leonard \& Barton, 2011).

When a company develops a new product, consumer needs need to be prioritized to gain acceptance and loyalty in the industry. The dynamic nature of customer needs has been found in research to be as a result of changes in the innovative environment. The view and expectations of customers towards such products

Saeed A. Mousa, Lecturer, M.Sc. in Economics, Palestine Technical University, Tulkarm, Palestine.

Correspondence concerning this article should be addressed to Saeed A. Mousa, Kadoorie University, Yaffa Street, P.O. Box 7, Tulkarm, Palestine. 
therefore grow more positive. This kind of study has been conducted on targeted demographics, producing data at a minor level. In the field of research, it is advised that a company should keep in mind the products of its competitors and its own ability in mind whenever it develops an innovative product (Anderson \& Mittal, 2012). A company's resources, therefore, should be saved to be used when it is working on an innovation in a product. A firm's managers should be mindful of the resources that they are using and those needed for the development of a new product (Anderson \& Mittal, 2012).

According to Zhang (2011), the satisfaction of customers' needs refers to their response to the condition of fulfillment and the statement of accomplishment. The satisfaction of the consumers' desires leads to customer loyalty. Customer loyalty to a brand is key for the survival of a business in today's competitive environment.

The present business environment requires constant competition, attention to every-changing customer needs, rapid technical changes (Montoya \& Workman, 2012). With these considerations, Damanpour and Gopalakrishnan (2011) assert that innovation is a critical factor for organization's success in obtaining a sustainable competitive advantage and success. That is because innovative organizations are flexible and able to respond quickly to change. When it comes to creating new opportunities and the exploitation of new ones, innovative firms are characterized by the willingness to go the extra mile, and to experiment with new and unproven products (Drucker, 1985). Empirical research concurs with the positive relation between innovation and performance (Damanpour \& Gopalakrishnan, 2011).

Given the fundamental role of innovation in improving the performance of a business, many types of research have given attention to the identification of the factors that influence change. Currently, one key variable has been established that affects innovation, which is organizational culture (Laursen \& Salter, 2011). Since organizational culture affects employees' behavior, it may influence personnel to accept and get involved in innovation as a fundamental value of the organization.

Zhang (2011) argues that when a firm develops a new product whose functionality needs technical assistance, the product's reliability increases its uniqueness. Laursen and Salter (2011) demonstrate that development of innovative new products increases customer satisfaction and as a result, in the view of the customer, the product's value is increased.

Researchers have determined that customer satisfaction is affected by both the innovation climate and culture. There is such rapid development that companies must constantly be on the alert to trends and changes in the industry. The technological advances in the global business environment have led to a figurative arms race, with each corporation attempting to invent the next best product capability or feature. It is against that backdrop that this paper will focus on establishing the effect of innovative climate and culture on customer needs and loyalty.

This research involves mobile phones and is conducted in a university setting. This is because mobile phones are almost ubiquitously used amongst this demographic. When mobile phone companies introduce new innovative products in the market, it affects the expectations of the university community on the same product and thus their future needs met by the phone companies. The paper, therefore, determines the extent to which the innovative climate and culture affects customer expectations.

\section{Literature Review}

\section{Innovation}

Innovation is a process that is vital to many different fields across the world, which enables them to be 
more successful than their competitors. Innovation can also be customer driven, especially when a feature that does not meet customer expectations inspires that innovation. Innovations in organizations can be either small or big in different companies at different times. In some cases, they are the limited changes that a company makes a product or in other cases; circumstances of the companies introduce a very new product to the market. These changes in products are intended to increase existing customer satisfaction, attract new customers, and extend the boundaries of their markets.

Rao et al. (2001) defined innovation as a continuous discovery process that involves learning, application of new and existing techniques, and modern technology. Innovation is a key strategy for competition for most businesses in the world. If a company or a business enterprise has to keep pace with the world's changing demands, it must be innovative. If they are unwilling to change their product to meet customer expectations, companies will be unable to compete in the modern world. There are two types of innovation: product innovation and process-based innovation. Firms with the high level of technology mostly focus on product innovation, in which they attempt to produce new products to attract more customers and increase their market share. Organizations with a low level of technology most likely concentrate more on the process-based innovation with an objective of cutting down production cost. This results in being able to lower the consumer's price while still making their profit margin.

Innovation is important for modern global economies because it results in economic development, growth, and improvements in products and technology. From the perspective of personnel, this constant innovation requires either consistent training of existing employees, or the hiring of new employees who possess the necessary skills. As innovation brings about economic development and growth, it creates new employment opportunities, as well as expanding and modifying the already existing jobs. Mobbs (2010) argues that this type of job modification leads to the overall improvement of the entire firm.

Laursen and Salter (2011) explain that innovation is a major factor for development for the past decades and the present. However, the amount of money that organizations invest today has far surpassed anything in the past. Firms also train their personnel to be able to generate new ideas that are used to improve existing products. Laursen and Salter (2011) further explain that firms spending massive amounts of resources and time searching for new ideas and opportunities are more innovative than their counterparts that do not invest in knowledge. It is further argued that in the present day, firms are interested in working with an open innovation model concept. According to this model, successful firms spend less funds on the internal affairs of the firm, but invest massively in external affairs such as acquiring knowledge and expertise, which in turn brings new solutions for customer expectations.

\section{Customers Needs}

According to Singh (2012), the satisfaction of customers' needs is of great importance to firms because it is directly proportional to the firm's profitability. If customers are satisfied with the brands and products of a firm, they will purchase more from the firm that produces these products, and consequently the firms realizes increased profits. Satisfaction of customers' needs is multidimensional: if companies deliver mean values to their clients, then it implies that the firm is attempting to satisfy them. Research by Leelakulthanit and Hongcharu (2011) concluded that cellular companies that introduce products in the market had to differentiate their products from those of the other firms to maintain and satisfy their customers. The research further concludes that satisfying customers' needs involves the utilization of new technology to boost the quality of 
services. The new technology and services surpass the old and outdated services. Improvement of the existing products directly causes customers to purchase more of the products and thus boosting firm's sales. Therefore, by extension, innovation will lead to customer loyalty, increased revenues, and customer satisfaction.

According to Reichheld (2012), all firms rely on customers, and should therefore focus more on customer needs, and afterward come up with new products and ideas according to the demands of their customers. The organizations need not consider the customers as a burden to the firms because they are the primary sources of revenue to the businesses. Customer satisfaction is a vital aspect of building customer loyalty to the brand. Without the element of satisfying specific customers' needs that others do not, customers will have no particular brand to identify themselves with and will have no preference.

The satisfaction of customer needs is defined by the difference between the perceptions they have and their expectation (Koskela, 2012). Research proposes the use of different methods by firms to ascertain the satisfaction level of customers. The methods included customers' suggestion and complaint system, satisfaction surveys for customers, analysis on lost customers, and customer behavior about consumption behavior.

\section{Brand Loyalty}

The establishment of brand loyalty takes place through the repurchase behavior of the consumer (Basswari, 2012). It is the habit of purchasing one brand and then repurchasing the same brand repeatedly. The continuous utilization of a particular brand makes a customer more loyal to the brand. According to Mao (2010), brand loyalty is the customers' preference to purchase a particular commodity or product or service. Once a customer is a faithful follower of a particular brand, it becomes more likely that they will be willing to stay with the product through price raises because of the satisfaction the product brings them. The customers will feel that their brand could be better than other existing brands and, therefore, will value the product and services of specific brands.

Reichheld (2012) argues that attracting new customers to firms cost six times more than maintaining the existing clients. The attraction of new customers to purchase the product of a firm is very expensive because it involves sales, advertisement, promotions, and other expenses such as operating costs. He discussed that customer loyalty to a firm is critical for several reasons: firstly, it is cheaper to maintain loyal customers than to attract new customers to start purchasing your brand; secondly, he explained that loyal customers are far more likely to give positive feedback towards their preferred brand.

According to Dachyar and Fatkhurrohman (2011), the attainment of customer loyalty takes place through commitment and customers' confidence. In order to achieve customer loyalty, people must feel that they are receiving appropriate services or products for the money they are spending. Loyal customers buy the same brand repeatedly because they feel satisfied.

A study by Rowley (2005) argued that there are four categories of customer brand loyalty. The study identified the categories as consisting of: convenience customers, captive customers, satisfied customers, and faithful customers. Captive customers are those who buy the same products and services because they lack alternative brands to purchase. Convenience customers are those who purchase the brands that are easily accessible, but they do not have a particular preference about the brand. Committed customers tend to be active with both behavior and attitude. Committed customers are the best loyal customers for a firm. Satsified customers have a positive attitude towards a particular brand, but they can never purchase the same products at slightly higher prices. Anderson and Mittal (2012) concluded that faithful customers are a source of growth, 
profitability, and an asset to businesses. In essence, the difference between a satisfied and a faithful customer is whether they have the financial stability to follow a brand through a price change.

\section{Innovation and Performance}

There is a variety of ways in which the conceptualization of innovation has taken place (OECD, 2005). These include the implementation of an improved product or service, new marketing methods, production process, external relations, workplace organization, or new organizational methods defines innovation (OECD, 2005). Innovation can be broken down into four different categories of innovation including product innovation, process innovation, organizational innovation, and marketing innovation (OECD, 2005).

Product innovations include adjustments in the capabilities and features of goods. Process innovation, on the other hand, involves changes in delivery and production methods. Organizational innovations entail new methods that can be alterations in business practices, workplace organization, or a firm's external relations. Marketing innovations are the implementations of new methods of marketing, which includes product design and packaging, product placement and promotion, and pricing methods for goods and services.

In general, innovation is an important driver for business success in the long-term, especially in the current dynamic market (Damanpour \& Gopalakrishnan, 2011). The rationale of the idea of innovation is that it serves to counter the external business environment that is generally quite turbulent. Therefore, firms must be able to live up to the task of coping with the increasing complexity and rapid change. In such contexts, enterprises with better capabilities to innovate will find it easier to adapt faster to new challenges, exploit new opportunities in the market, and manufacture new products better than the non-innovative companies.

Many types of research have highlighted the positive impact of innovation on the performance of firms (Damanpour \& Gopalakrishnan, 2011). Therefore, empirical research and theory suggest a significant relation between performance and innovation (Zhang, 2011). The first hypothesis proposed is that a firm's innovation exhibits a positive association with its performance.

\section{Organizational Culture and Innovation}

Many studies have focused on establishing the major determinants of innovation given its importance in the processes of firms (Crossan \& Apaydin, 2010). Innovation occurs at many different levels, which are split up into categories that include individual, organizational, and environmental levels. Considering the organizational level, literature refers to size, strategy, organizational strategy, human resource practices, organizational culture, leadership, and financial support. The key levels that stand out are the organizational culture and design (Damanpour, 2011).

Reichheld (2012) defines organizational culture as the beliefs, values, and hidden assumptions that are subscribed to by members of an organization. The value system of a team affects the behavior and subsequent productivity either positively or negatively, depending on the internal integration and coordination. Culture can act as a stimulant for innovative behavior within an organization. That is because it can influence employees towards the acceptance of innovation as a fundamental value in the organization, and to exhibit commitment to it.

\section{Methods}

This section describes the respondents and methods of data collection.

\section{Questionnaire}

A quantitative method was used to conduct this study. One question that was adopted was that reliability 
and validity were already checked. Nemati, Khan, and Iftekhar had designed the questionnaire in 2010 (Kapferer, 2012). This questionnaire was used to collect data. The scale consisted of 27 items in number. A Likert scale was used in the measurement of the variables. Approximately 100 questionnaires were distributed. Eighty-five questionnaires were received back, resulting in an $85 \%$ response rate.

\section{Location of the Study}

The study is going to be carried out in Chinese universities including Peking and Tsinghua Universities. This country is selected due to the rapid nature of its mobile industry. The Chinese mobile industry boasts of approximately 50 percent of the global market share owing to the current strength in innovation.

\section{Population and Sample}

The subjects of this research purely consisted of university students, teaching and non-teaching staff in China. A convenient sampling technique was used, and questionnaires were administered to the university fraternities that were smartphone users.

\section{Statistical Analysis}

Data collected through the questionnaires were analyzed using SPSS software. The data were also analyzed using correlation and regression methods. The correlation analysis revealed a positive relationship between variable innovation and satisfaction of customer needs and the resultant brand loyalty. The regression analysis also established the strength of the strength between the variables. Innovation was classed as an independent variable, and customer needs satisfaction as intervening and brand loyalty as a dependent variable.

\section{Correlation Analysis}

Table 1

Correlation Analysis of the Data

\begin{tabular}{lll}
\hline & Innovative climate and culture & Customer needs satisfaction \\
\hline Customer needs satisfaction & 0.753 & \\
Brand loyalty & 0.731 & 0.738 \\
\hline
\end{tabular}

$\mathbf{N}=\mathbf{8 5}$ and correlation is significant at the level $\mathbf{0 . 0 1}$. The correlation analysis shows that there is a positive correlation between customer needs and innovative climate and culture. Brand loyalty, the second variable, has a significant relationship with innovative climate and culture. Brand loyalty and customer needs satisfaction also show some correlation and show a highly significant relationship. The relationships demonstrate that the variables affect each other and an acceptance of the hypothesis among the respondents.

\section{Regression}

In Table 2, $\mathrm{R}$ indicates that innovative climate and culture highly explains customer needs. This shows that a positive relationship exists between innovative climate and culture, and customer needs. The $\mathrm{R}$ value is 0.741 indicating that innovative climate and culture affects customer needs.

Table 2

Innovative Climate and Culture (Independent Variable) Customer Needs (Dependable Variable)

\begin{tabular}{lllll}
\hline Model & $\mathrm{R}$ & Adjusted R square & R square & Standard error of the estimate \\
\hline 1 & 0.741 & 0.560 & 0.583 & 0.28131 \\
\hline
\end{tabular}




\section{Coefficients (a)}

Table 3 shows the coefficient of innovative climate and culture and customer loyalty. The Beta value indicates that a unit change in the innovative climate and culture will change $0.582 \%$ of customer loyalty. The standard error column reveals that the error describing the relationship between the two variables is very insignificant. The error in the last column is 0.000 , implying that there is the high significance of innovative climate and culture on customer loyalty.

Table 3

Coefficient of the Model

\begin{tabular}{|c|c|c|c|c|c|}
\hline \multirow{2}{*}{ Model } & \multirow{2}{*}{$\begin{array}{l}\text { Standardized } \\
\text { coefficients } \\
\text { beta }\end{array}$} & \multicolumn{2}{|c|}{$\begin{array}{c}\text { Unstandardized } \\
\text { coefficient }\end{array}$} & \multirow[t]{2}{*}{$\begin{array}{l}\mathrm{t} \\
\mathrm{B}\end{array}$} & \multirow[t]{2}{*}{$\begin{array}{l}\text { sig. } \\
\text { Std. error }\end{array}$} \\
\hline & & $\mathrm{B}$ & Std. Error & & \\
\hline \multirow[t]{2}{*}{ Innovative environment and culture } & 0.682 & 1.072 & 0.243 & 4.224 & 0.000 \\
\hline & & 0.582 & 0.065 & 8.223 & 0.000 \\
\hline
\end{tabular}

\section{Regression}

Table 4

Independent Variable: Customer Needs Dependent Variable: Customer Loyalty

\begin{tabular}{lllll}
\hline Model & $\mathrm{R}$ & Adjusted R square & R square & Std. error (estimate) \\
\hline 1 & 0.687 & 0.532 & 0.555 & 0.27031 \\
\hline
\end{tabular}

Table 4 shows that customer needs have high impacts on customer loyalty. It shows that there is a significant relationship between innovative climate and culture, and customer needs. The value of $\mathrm{R}$ reveals that customer needs and satisfaction has an immense effect on customer loyalty. Customer loyalty, therefore, increases with a rise in customer needs satisfaction.

\section{Descriptive Statistics}

Table 5

Variation From the Origin

\begin{tabular}{llll}
\hline & Mean & std. deviation & $\mathrm{N}$ \\
\hline Innovative climate and culture & 3.3776 & 0.32543 & 85 \\
Customer needs & 3.5245 & 0.38221 & 85 \\
Customer loyalty & 3.3443 & 0.40492 & 85 \\
\hline
\end{tabular}

Table 5 shows that there is significant mean of the variables that indicates good propensity of the population to concur with the hypothesis. The standard deviation provides a description of the variation from the origin. The variations are, to some extents, bearable.

\section{The Process of Acceptance of a New Product}

Figure 1 shows the process of market penetration of a new product in the product is introduced in a market; it goes through a various stages of acceptance by consumer from innovators to laggards. The innovators constitute the first group to try to accept the new product and constitutes of approximately 2.5 percent of consumers while laggards (16 percent) is the last group that try the new product once everyone else has accepted the product. 


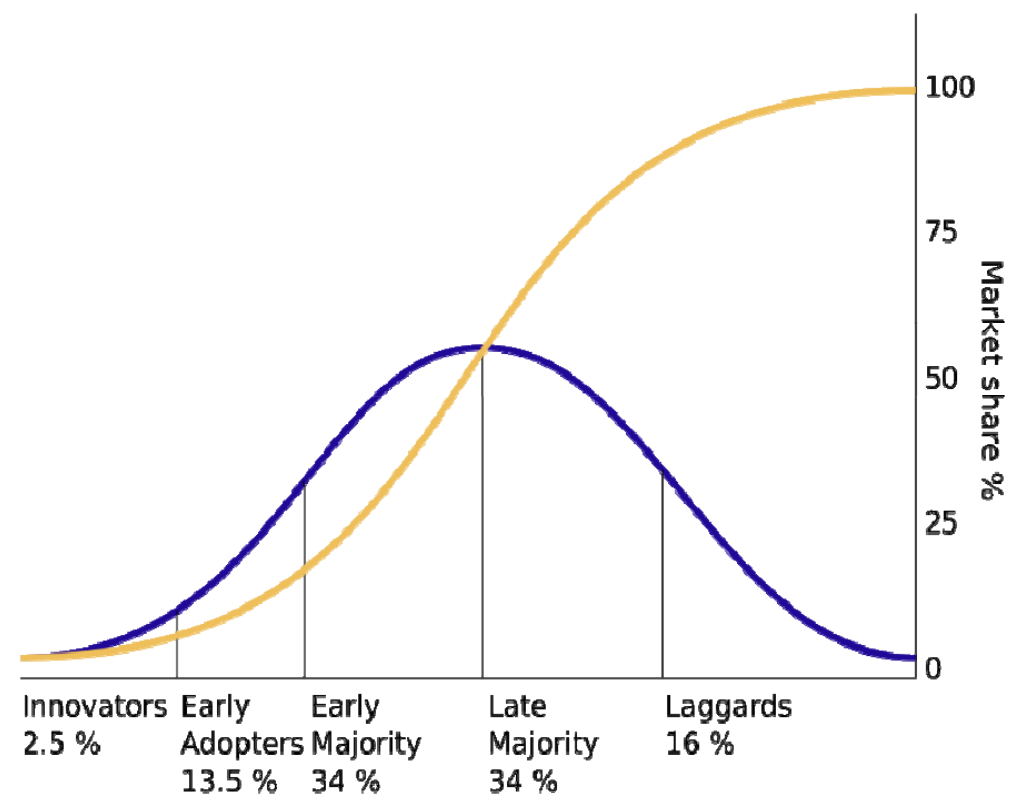

Figure 1. Process of acceptance of a new product.

\section{Relationship Between Customer Satisfaction and Customer Loyalty}

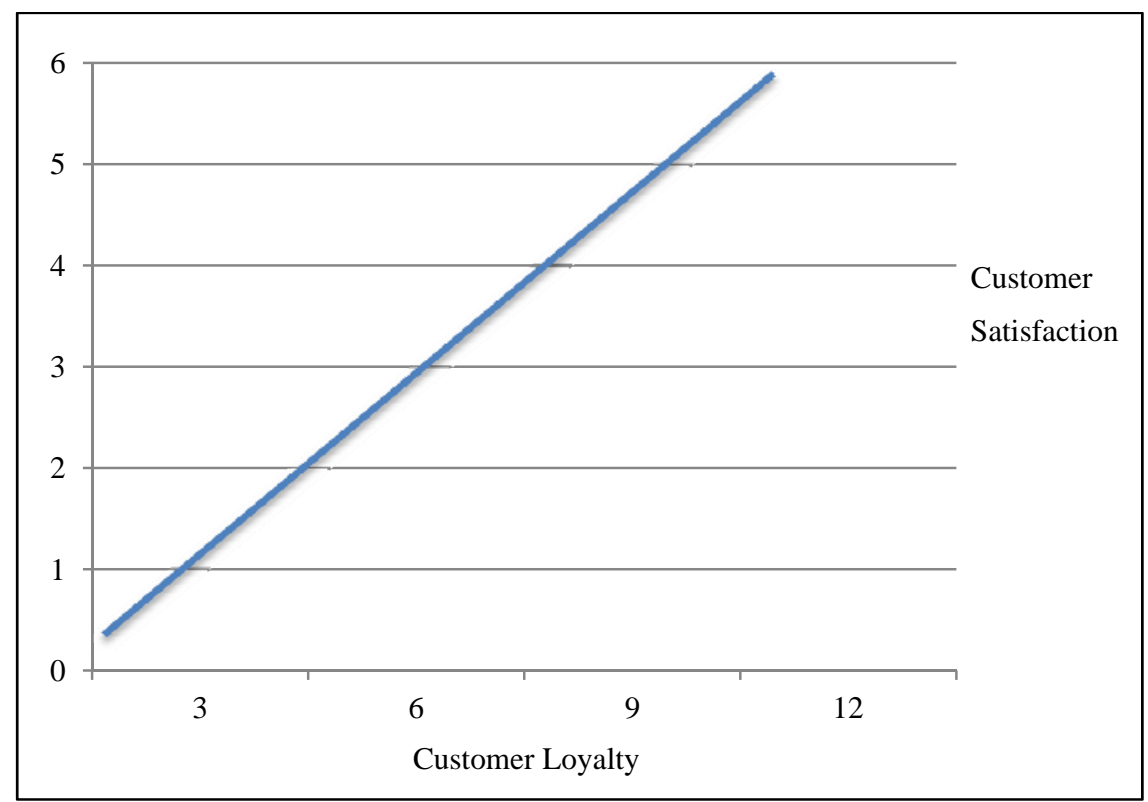

Figure 2. Relationship between customer satisfaction and customer loyalty.

Figure 2 shows the relationship between customer satisfaction and customer loyalty. The figure presents a direct proportionality between customer loyalty and customer satisfaction. An increase in the level of customer satisfaction leads to an increase in loyalty among consumers.

\section{Relationship Between Innovative Climate and Culture, and Customer Needs}

Figure 3 shows a positive relationship between innovative climate and culture on customer needs. Changes in the business environment due to innovation lead to significant changes in the needs of customers. 


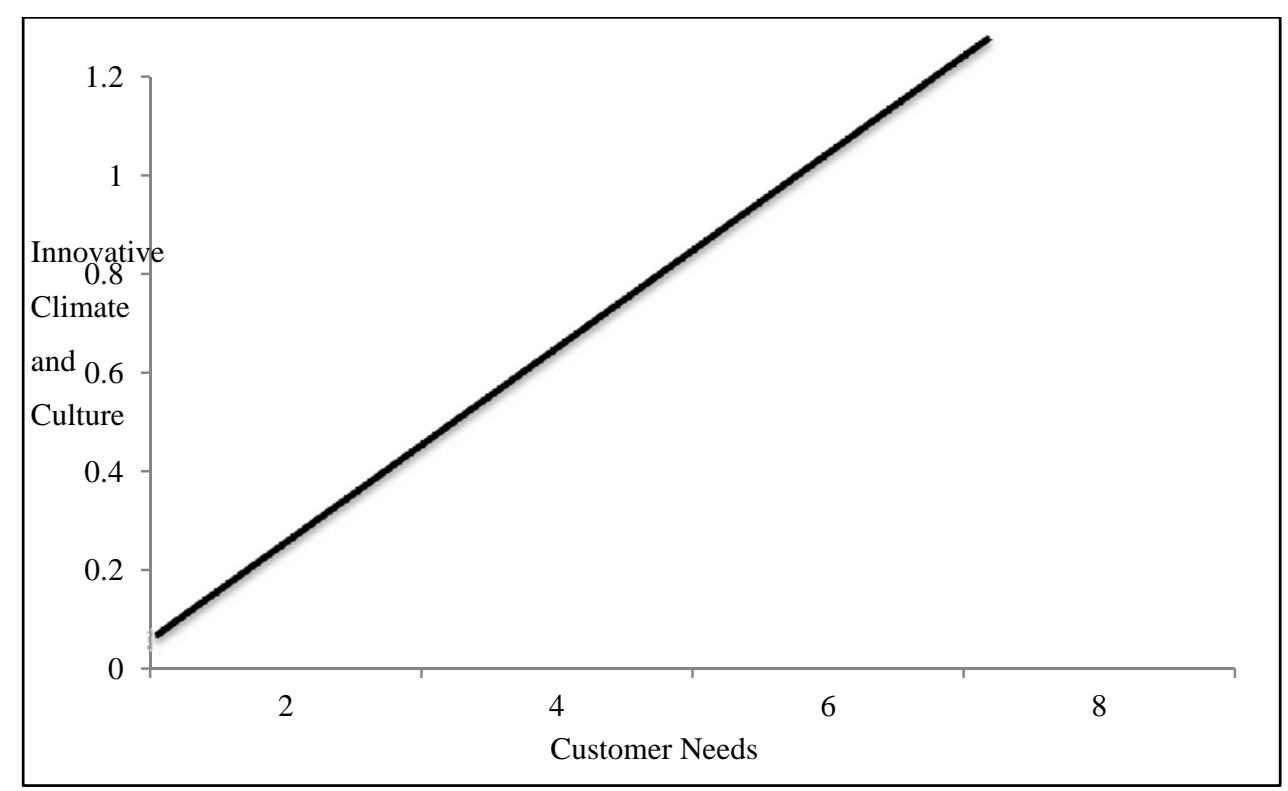

Figure 3. Relationship between innovative climate and culture, and customer needs.

\section{Discussion}

This research describes the impact of innovative climate and culture on customer needs. The findings indicate that an innovative climate and culture has a positive impact on customer's needs. The results of the study show that the relationship between an innovative climate and culture and customer needs is unyielding.

As the innovative climate and culture in an industry undergo changes, customer needs are also affected. Innovations in an industry in terms of new additions raise customer expectations of similar products. Customers

will be therefore in need of advanced products that address emerging challenges that come from the advancement in technologies, as for the case of mobile phones. In the market for the mobile industry, especially within a university context, companies have the potential of acquiring a competitive edge by providing more advanced and efficient products that meet their needs at a given time. Customer's needs and desires must constantly be monitored if the business is to have a chance of keeping up with industry trends.

The findings also suggest that innovative climate and culture has a positive relationship with customer loyalty. Loyal customers are valuable assets to business enterprises because they are likely to purchase a product over a very long period. The cost of acquiring new customers is more than that of retaining the existing ones. When companies in the mobile phone industry launch new products, students purchase them. They tend to stick to a particular company until it supplies them with new products that meet emerging trends in the mobile phone industry.

Due to the high competition in innovation to win more customers, the industry is forced to foster an innovative climate. With the rapidly changing trends in the business environment, customer needs are also affected. Such changes, especially in technology, influence the needs of customers. Trends in technology in the mobile phone industry influence changes in customer need. That is because they tend to demand products that are up to advances in technology.

The acceptance of the third hypotheses of the study shows that there is a strong relationship between satisfaction of customer needs and customer loyalty. That revealed that the students repurchased products that 
satisfy their needs. When a brand provides innovative products that successfully meet the needs of customers, customers tend to be reluctant in switching to other brands. The trends change so quickly that what was the hottest innovation recently is replaced and made irrelevant. That is due to the high level of competition among companies in the line of innovation. The needs of customers are also changing at a rapid pace that players in industries attempt to keep up with. Old technologies and capabilities in an industry become inadequate in meeting future needs. If a company desires a long-term survival, it has to work to initiate customer loyalty. Creating and fostering customer loyalty requires that a company understands the needs of its customers, and the factors that influence those needs. One of the major factors that have been demonstrated by this research to be influencing customer needs is the innovative climate and culture in the industry.

The results of the study describe the relationship between innovative climate and culture, and between customers' needs satisfaction and customer loyalty. The results indicated that an innovative environment and culture influences customer needs and loyalty. The aim of this study was to provide information on the effects of an innovative climate and culture on customer needs. Concerning future study, researchers can conduct research by using variables from this study to assess the relationship between the variables. The university fraternity who use mobile technology in the industry can include the coverage of the whole market of students.

\section{Conclusion}

The level of competition in the global business arena has rapidly increased. Companies face different forms of challenges in their pursuit to satisfy the needs of their customers while taking into consideration the constant changes in technologies. The operational industry of the organizations has become relatively dynamic and complex, hence the need to remain relevant and offer viable competition. Getting customer loyalty through innovation has therefore been a hard task in the industry.

The purpose of this study was to investigate the impacts of innovative climate and culture on customer needs. The assessment incorporated the involvement of two measure of client needs. The measures under exploration were customer loyalty and customer satisfaction. There is an investigation of effects of innovative climate and culture on customer needs through an analysis of the relationship between innovation, and customer needs satisfaction and brand loyalty. To generate hypotheses, the study applies the use of a literature review to identify a gap in the existing research studies. The study collected data by using questionnaire from 85 respondents. Simple linear regression and corresponding correlations were used to analyze the collected questionnaires.

The results of the study show a positive relationship between innovative climate and culture, and customer needs, satisfaction, and brand loyalty. That also indicated a significant association between customers' needs satisfaction and brand loyalty. This study is unique in the sense that it only investigates the university community as the users of the mobile market. Therefore, the study provides the way to marketers and researchers in focusing on the particular category of consumers; especially mobile researchers on a way to conduct studies by the variables mentioned above among other groups of mobile users.

\section{References}

Anderson, E. W., \& Mittal, V. (2012). Strengthening the satisfaction-profit chain. Journal of Service Research, 3, 107-120.

Dachyar, M., \& Fatkhurrohman. (2011). The effect of innovation factors to customer loyalty by structural equation model. World Academy of Science, Engineering and Technology, 76, 845-849. 
Damanpour, F., \& Gopalakrishnan, S. (2011). The dynamics of the adoption of products and process innovations in organizations. Journal of Management Studies, 38, 45-65.

Koskela, H. (2012). Customer satisfaction and loyalty in after sales service: Modes of care in telecommunications systems delivery. Helsinki University of Technology, Department of Industrial Engineering and Management, Finland.

Kapferer, J.-N. (2012). The new strategic brand management: Advanced insights and strategic thinking. London: Kogan Page.

Laursen, K., \& Salter, A. (2011). Open for innovation: The role of openness in explaining innovation performance among U.K. manufacturing firms. Strategic Management Journal, 27, 131-150.

Mao, J. (2010). Customer brand loyalty. International Journal of Business and Management, 5(7), 213-217.

Mobbs, C. W. (2010). Why innovation is important? Innovation for Growth, 1-4.

OECD, \& EUROSTAT. (2005). Guidelines for collecting and interpreting innovation date -Oslo manual (3rd ed.). Paris: Organisation for Economic Co-operation and Development and Statistical Office of the European Communities.

Reichheld, F. F. (2012). The loyalty effect. Boston, MA: Harvard Business School Press.

Zhang, M. (2011). Firm-level performance impact of IS support for product innovation. European Journal of Innovation Management, 14(1), 118-132. http://dx.doi.org/10.1108/14601061111104724 